\title{
Conflitos hídricos na gestão dos reservatórios Billings e Barra Bonita
}

CLAUDio LUIS DE CAMARGO PENTEADO I, DANIEL LADEIRA ALMEIDA II

e ROSELI FREDERIGI BENASSI III

\section{Introdução}

$\mathbb{Q}$ M 2015, a água servida ao abastecimento público concomitante a geração da energia hidrelétrica foi responsável pela produção de $64 \%$ da eletricidade consumida em território nacional, segundo a Empresa de Pesquisa Energética (EPE, 2016).

Segundo a Organização para a Cooperação e Desenvolvimento Econômico, para atender tais demandas é necessário que a disponibilidade hídrica seja monitorada e gerenciada regionalmente, e instituições e políticas robustas são necessárias para fazer o melhor uso da água disponível (OCDE, 2015).

Esses fatores são desafios que exigem ações efetivas dos gestores que operam e se utilizam dos reservatórios. Tais agentes podem estar envolvidos em um modelo de gestão pública, em que há intervenção do Estado na atividade produtiva (Abranches, 1979) ou em um modelo de gestão privada, que visa à racionalização das atividades, afinando-se organização, regulação e planejamento territorial com os desígnios de grupos corporativos nacionais ou multinacionais (Ramalho, 2006).

Diante da contextualização apresentada, este artigo analisa a gestão de reservatórios em meio aos conflitos pelo uso da água, através de entrevistas realizadas com representantes de empresas públicas e privadas que operam e utilizam reservatórios construídos para a finalidade hidroenergética, e que foram vocacionados para o abastecimento público.

Os entrevistados participaram da pesquisa no terceiro trimestre de 2015, possuindo mais de cinco anos de atuação nas empresas, sendo três públicas, uma operadora (Emae) e uma usuária (Sabesp) das águas do reservatório Billings e outra encarregada de fiscalizar e monitorar a poluição (Cetesb); além de uma empresa privada (AES-Tietê) que opera as águas de Barra Bonita, incluindo a participação da Capitania Fluvial do Tietê-Paraná, como instituição atuante na fiscalização deste reservatório. As entrevistas, amparadas pela fundamentação teórica, buscam identificar as ações conflitantes entre os usuários e operadores dos 
reservatórios pelo uso da água, e, a partir de um processo de análise, propõem-se elaborar medidas que reduzam os conflitos pelo uso da água e contribuam na gestão dos recursos hídricos de forma a ampliar a produtividade de energia elétrica, mantendo ativos os usos múltiplos dos reservatórios.

A hipótese geral sustenta a ideia de que a análise dos conflitos pelo uso da água em reservatórios pode contribuir na compreensão da gestão das empresas que sobre eles atuam e subsidiar a análise dos passivos ambientais existentes nos reservatórios.

Os reservatórios Billings (localizado na Região Metropolitana de São Paulo) e Barra Bonita (localizado no interior do estado de São Paulo) constituem importantes mananciais que servem ao abastecimento público. Mesmo construídos para geração de energia elétrica, em especial o reservatório de Barra Bonita, concebido também para servir ao transporte fluvial, ambos foram vocacionados ao abastecimento público. Dessa forma, o objetivo desta pesquisa é contribuir na melhora da gestão compartilhada dos reservatórios, reduzindo os conflitos pelo uso da água potencializada para abastecimento público e produção de energia elétrica, com a finalidade de reduzir os passivos ambientais que atingem tais reservatórios.

\section{Gestão pública e privada em reservatórios hidrelétricos}

Os movimentos de privatização ou de estatização, independentemente das suas motivações econômicas ou políticas, têm como objetivo superar gargalos institucionais para reverter uma situação de estagnação no modelo gestor vigente (Vargas, 2005). Isso significa que a transferência da gestão para a iniciativa privada não pode ser vista como a alternativa salvadora dos gargalos de investimentos que atingem os setores públicos, mas como um processo dinâmico relacionado à tentativa de superar dificuldades financeiras e institucionais que possam estar impedindo o desenvolvimento da infraestrutura e dos serviços.

Porém, o processo de privatização do setor elétrico brasileiro foi eivado de irregularidades, e distante de um amplo debate na sociedade acerca de suas possíveis consequências para os destinos da nação e de seus recursos naturais, em particular seus recursos hídricos. Além de não discutir, com seriedade, os aspectos socioambientais (Vainer, 2007).

O modelo de gestão pública procura minimizar as oportunidades de atrair capitais privados para que sejam ampliadas e melhoradas as suas infraestruturas, e dificulta a possibilidade de transferência de tecnologia avançadas e incentivos ao incremento da eficiência global do setor, resultado da competitividade em mercado mundializado (Vargas, 2005).

O modelo de gestão privado está sujeito aos abusos do poder econômico, pois não se pode prever o comportamento dos gestores privados em termos de padrão de investimentos, eficiência ou conduta oportunista (Vargas, 2005). Dessa forma, o gestor privado se prevalece das flexibilizações existentes na legislação que enquadra a concessão, o contrato, à autonomia dos órgãos 
reguladores e o capital social acumulado no município, estado ou região na forma de instituições que reivindicam o direito a participação e transparência na gestão dos reservatórios, os quais têm a água como um recurso de interesse público.

A gestão de reservatórios, seja pública, seja privada, é dinâmica e complexa, pois surgem novas variáveis que alteram todo o conjunto de conflitos estabelecidos, de forma que os sistemas estanques de gestão estão sujeitos ao insucesso.

A gestão dos reservatórios deve estar em consonância com a gestão de bacias hidrográficas. E com a gestão integrada de bacias hidrográficas articulada com o planejamento regional pode ser eficiente instrumento de desenvolvimento socioambiental e econômico, possibilitando novas alternativas de múltiplos usos, associados à garantia da qualidade da água dos tributários do reservatório (Campagnoli; Tundisi, 2012).

No Brasil, é comum o Estado desempenhar o papel principal no cumprimento das metas de universalização de acesso a energia elétrica e saneamento. Entretanto, o setor público está distante de ser o melhor e único provedor dos interesses coletivos da nação, pois planejadores e funcionários públicos atuam com os mesmos princípios do setor privado, ao buscar maximizar seus objetivos reservados ao seu setor em detrimento dos interesses econômicos da coletividade para a qual trabalham.

Contudo, a solução para tais consequências não consiste na execução da privatização ou estatização das atividades exercidas nos reservatórios. Mas reunir esforços para criar ambientes institucionais que ofereçam incentivos adequados para que os agentes econômicos e autoridades públicas minimizem as condutas oportunistas; com isso reduzindo os riscos e os custos de transação (Vargas, 2005). Assim sendo, a gestão de reservatórios, seja pública, seja privada, deve procurar manter a reserva hídrica dos reservatórios como garantia à geração de energia, e gerir os reservatórios além da busca de ampliar dividendos financeiros, e fundamentar programas ambientais que contemplem demais usuários do reservatório.

\section{Breve contextualização dos reservatórios Billings e Barra Bonita}

A gestão nas usinas hidrelétricas Billings e Barra Bonita foi analisada na óptica de que as responsabilidades de conservação dos reservatórios não se restringem às empresas de saneamento e de geração de energia, mas como um instrumento de inserção e integração entre diversos atores que ocupam os domínios territoriais do reservatório hidrelétrico.

Os primeiros empreendimentos hidrelétricos construídos em São Paulo tiveram seus conflitos socioambientais ofuscados pela necessidade de crescimento econômico, em uma época na qual predominava a ideia de que os recursos naturais eram inesgotáveis e as demandas sociais e ambientais poderiam ser supridas apenas pelo desenvolvimento tecnológico e industrial. 
Essa concepção se perpetuou até o início da década de 1950, momento de construção da usina Barra Bonita, sem que houvesse os parâmetros previstos nos Estudos ou Relatórios de Impactos Ambientais, como prevê a Resolução n.001, do Conselho Nacional de Meio Ambiente (Conama) de 1986. Nessa época somente o Código das Águas (1934) regulamentava o aproveitamento dos recursos hídricos, ademais, antes dessa legislação as normas de uso da água datavam do período colonial brasileiro (Massei, 2007).

Esse modelo tratava os conflitos no âmbito dos órgãos especializados do poder executivo federal por meio do extinto Departamento Nacional de Águas e Energia Elétrica, de forma a atender as prioridades do poder central, onde a resolução de conflitos se mediava conforme as forças locais e regionais e os interesses políticos e econômicos (Gomes; Barbieri, 2004). Portanto, distante de uma consulta pública entre instituições e entidades da sociedade civil organizada.

O complexo hidroenergético de Barra Bonita foi integralmente construído e, posteriormente, gerido pela iniciativa estatal até a década de 1990. Todavia, devido ao Programa Estadual de Desestatização iniciado em 1996, passa a ser de concessão da multinacional AES-Tietê, que também se responsabiliza pela operação da eclusa inserida na hidrovia do rio Tietê-Paraná. Com isso, intensifica a disputa pelo aproveitamento dos recursos hídricos entre as instituições locais e multinacionais.

O processo de privatização das estatais brasileiras foi acentuado pela queda de investimentos públicos na ampliação das empresas estatais e com a falta de modernização dos instrumentos que proporcionasse melhores qualidades dos serviços a ser atendidos para a população. Isso reforçou o argumento político favorável à privatização sob o argumento de que fossem ampliados os investimentos em prol da qualidade nos serviços públicos de saúde, educação e assistência social.

O apagão de 2001 sinalizou a falência técnica da reforma neoliberal do setor elétrico, a crise financeira das empresas privadas de energia elétrica, vinda a público no início de 2003 , evidenciou o fracasso econômico durante o governo de Fernando Henrique Cardoso (1995-2002), que exerceu um processo de privatizações ao qual desresponsabilizou a iniciativa privada das questões socioambientais (Vainer, 2007).

Orientada pelo comportamento estratégico destinado a privilegiar os interesses dos acionistas, as grandes corporações se distanciam dos objetivos e metas sociais a serem atingidas de maneira articulada com as prefeituras e a sociedade civil organizada (Vargas, 2005).

Ao privatizar sem critérios empresas de geração e distribuição de energia elétrica, e conceder a exploração dos potenciais hidrelétricos a grupos privados que raramente têm qualificação no tratamento das questões sociais e ambientais, o governo colocou em risco avanços socioambientais conquistados, pois a legislação a respeito de concessões foi omissa quanto ao tratamento a ser dado 
aos problemas sociais e ambientais decorrentes de grandes projetos hidrelétricos (Vainer, 2007).

Por isso, é necessário garantir maior transparência e participação das lideranças da sociedade civil organizada nas negociações que envolvem os trâmites de concessão dos serviços públicos à iniciativa privada, assim como fortalecer órgãos reguladores que irão exercer a fiscalização e exigir a execução dos contratos. Delegar à iniciativa privada a gestão de serviços públicos com transparência e eficientemente regulada pode ser uma alternativa para superar gargalos financeiros e os problemas políticos-institucionais da gestão pública (Vargas, 2005). Assim sendo, existe um esforço dos governos em garantir a aproximação da gestão privada nas ações desempenhadas pelo poder executivo.

Nesse sentido, exercer a privatização da geração e distribuição da energia elétrica tende a subestimar capacidade da gestão pública em gerir com eficiência os reservatórios e sistemas de distribuição de energia elétrica.

A partir da década de 1920 inicia-se, pela iniciativa privada, a construção do que viria a ser o complexo hidroenergético Henry Borden, que posteriormente será gerido pelo poder estatal. Em seu projeto previa a retificação do (antes) meândrico rio Pinheiros e o represamento de rios, riachos e córregos que antecedem as escarpas da Serra do Mar (Goldemberg, 2002). No caso da usina Henry Borden, a pouca eficiência na fiscalização nas áreas de mananciais do reservatório, somada à falta de universalização da coleta e tratamento de efluentes nas cidades da Região Metropolitana de São Paulo contribuíram para a degradação dos corpos hídricos dos arredores da bacia do rio Tietê. Esse fato impossibilita o bombeamento contínuo de suas águas por meio do rio Pinheiros para o reservatório Billings e, consequentemente, reduzindo em aproximadamente $75 \%$ a capacidade de geração de energia da usina Henry Borden em períodos de maior estiagem (São Paulo, 2010).

Caso fosse permitida a transferência das águas do Tietê para o reservatório Billings, dada a grande produtibilidade da geração em Henry Borden, o volume de água retirado da usina de Barra Bonita afetaria minimamente a produção de energia elétrica nos reservatórios de acumulação de Barra Bonita, Promissão e Porto Primavera, que são utilizados para regular a vazão de água no Tietê (Gramulia Jr., 2009).

Em 1989 a Constituição Estadual, admitindo situação peculiar e crítica, sob o ponto de vista da qualidade das águas, no sistema Tietê-Pinheiros-Billings, e considerando a priorização do reservatório Billings para o abastecimento público, determinou, no art. 46 das Disposições Transitórias, um prazo de três anos aos Poder Público Estadual e Municipal para adoção de medidas eficazes no sentido de impedir o bombeamento de águas servidas, dejetos e outras substâncias poluentes para o reservatório Billings. Essa medida fez reduzir a geração de energia na usina Henry Borden para menos de $15 \%$ de sua capacidade de geração de energia elétrica (Gramulia Jr., 2009). 
O reservatório Billings, idealizado e construído, inicialmente, para garantir a produção de energia elétrica, emergia em suas nascentes aproximadamente 28 $\mathrm{m}^{3} / \mathrm{s}$, atualmente se encontra reduzido para menos de $14 \mathrm{~m}^{3} / \mathrm{s}$ anuais, segundo o Instituto Brasileiro de Proteção Ambiental (Proam, 2006). Essa redução no aporte hídrico é resultado do assoreamento dos seus afluentes a aterramento de suas nascentes promovidas pelas ocupações impulsionadas principalmente por infraestruturas viárias (rodovias Imigrantes, Anchieta e Rodoanel-trecho sul) que atingem aos mananciais do reservatório (Almeida, 2010).

Segundo Almeida (2010), para constatar os impactos ambientais provenientes do assoreamento do reservatório foi realizada entrevista com os responsáveis da Cetesb, da Sabesp e da Emae sobre o quanto avançou o processo de assoreamento. E todos os respondentes foram unânimes ao afirmar que não existe um acompanhamento efetivo e periódico do processo de assoreamento em diferentes localidades do reservatório Billings.

\section{Materiais e métodos}

Esta pesquisa almejou elucidar os objetivos com foco em informações qualitativas, coletadas em entrevistas conduzidas dentro de processos éticos, as quais procuram respeitar as ideias dos(as) entrevistados(as) sem alterá-las, mantendo a coerência dos objetivos da pesquisa. Os questionamentos direcionados aos(às) entrevistados(as) no terceiro trimestre de 2015 procuram analisar criticamente a gestão pública do reservatório Billings e a gestão privada do reservatório de Barra Bonita, buscando compreender os conflitos socioambientais que envolvem o uso dos reservatórios, e analisar os principais passivos ambientais que atingem os reservatórios.

Os(as) representantes das respectivas empresas controladas pelo governo estadual, aqui denominados(as) por RE1 (Representante da Emae), RE2 (Representante da Emae), RS (Representante da Sabesp), RC (Representante da Cetesb), RA (Representante da AES-Tietê) e RF (Representante da Companhia Fluvial Tietê-Paraná), concordaram em participar explanando as suas contribuições para a análise crítica da gestão pública do reservatório Billings e privada do reservatório de Barra Bonita, buscando compreender possíveis conflitos socioambientais que envolvem o uso dos reservatórios, e analisar os principais passivos ambientais que atingem os reservatórios. De todas as indagações feitas aos representantes da Emae, Sabesp, Cetesb, AES-Tietê e CFTP, foram selecionadas as questões que tiveram as respostas mais pertinentes aos objetivos deste artigo.

$\mathrm{O}$ destaque dos atores entrevistados na pesquisa não exclui importância da atuação de demais atores, pois os reservatórios hidrelétricos possuem diversas dimensões social, econômica e ambiental. Além de gerar energia elétrica, os reservatórios favorecem abastecimento público, atividades agrícolas, controle de enchentes, navegação fluvial, lazer, turismo etc.

O setor elétrico e de saneamento tem um papel cada vez mais relevante no aprimoramento de medidas de recuperação das áreas degradadas nos ma- 
nanciais dos reservatórios. Entretanto, é importante estimular os demais atores adjacentes aos empreendimentos hidrelétricos a desenvolverem ações integradas que visem melhorias nas condições socioambientais no local onde está inserido o reservatório.

\section{Resultados e discussão}

A legislação dos recursos hídricos consiste em um conjunto normativo de cunho cível, ambiental e administrativo, que determina as regras para domínio, uso e proteção da água, com a finalidade de garantir a melhoria da qualidade e quantidade disponível desse recurso. Além disso, as legislações visam regular o uso da água em detrimento da sua localização em relação aos grandes centros urbanos, e o crescimento da população, que expõe cada vez mais, a conflitos pelo uso da água, mesmo em lugares com hidrologia relevante (Granziera, 2014).

No que confere à Lei n.9.074 (Brasil, 1995), esta concede ao empreendedor o aproveitamento "ótimo" dos recursos hídricos na óptica de adequar o projeto à melhor forma de bom emprego econômico, desassociando dos aspectos sociais e ambientais que envolva a construção e manutenção do reservatório. Dessa forma, o reservatório é idealizado para garantir a eficiência energética e maximizar os lucros de usuários e operadores.

Portanto, concede à empresa detentora da hidrelétrica a operação dos recursos hídricos, considerado um bem público; e cumpre o seu papel quando atende os casos de prestação de serviços públicos de luz e energia. Entretanto, é necessário um grande esforço para explicar qual pode vir a ser a utilidade pública de um aproveitamento hidrelétrico no qual uma empresa privada utiliza um potencial hidrelétrico, que é patrimônio da nação, para abastecer exclusivamente uma planta industrial (Vainer, 2007).

É comum que, ao entregar à iniciativa privada as concessões para exploração de potenciais hidrelétricos, a Aneel aceite antecipadamente a licença, sendo fornecida antes da licitação. Em favor desse procedimento, seus defensores explicam que nenhuma empresa privada se interessaria em participar da licitação de um aproveitamento sem saber em que condições seriam obtidas a licença ambiental. Assim sendo, a empresa vencedora da licitação obtém a concessão sem ter assumido nenhum compromisso socioambiental por meio da participação de audiências públicas realizadas nos momentos do processo de licenciamento (Vainer, 2007).

Além de favorecer as empresas do setor energético, o contexto histórico de gestão dos recursos hídricos no Brasil ficou arraigado por práticas centralizadas e verticalizadas elencadas pelo Estado, principalmente a esfera federal, a qual foi responsável por definir prioridades, planejamento e gestão destes recursos, que perdurou por várias décadas (Jacobi et al., 2015).

Esse modelo de gestão se perpetuou até a criação da Lei n.9.433 (Brasil, 1997) ao instituir a Política Nacional de Recursos Hídricos, a qual oferece subsídios para estruturar os marcos regulatórios que priorizaram os usos múltiplos da água e a mediação de conflitos gerados pelo seu uso. 
Dessa forma, se rompeu com a hegemonia exercida pelo setor hidrelétrico em questões relacionadas aos recursos hídricos desde o início do processo de industrialização brasileiro, quando a energia passou a ser o principal insumo da modernização industrial brasileira e as hidrelétricas eram o maior vetor das grandes obras públicas (Gomes; Barbieri, 2004).

Mesmo que haja investimentos, o novo Código Florestal exclui a proteção de nascentes intermitentes, contemplando apenas as nascentes perenes, e suspende a proteção de faixas marginais de cursos hídricos efêmeros, colocando efetiva proteção dos recursos hídricos (Tambosi et al., 2015). Nesse caso, a legislação favorece a ocupação humana em detrimento da conservação dos recursos hídricos, deixando mais suscetíveis aos conflitos.

A demanda pelos recursos hídricos contribui na definição dos parâmetros para mediação dos conflitos. De certa forma, os principais embates ocorrem na formação de reservatórios de vazão para usinas hidrelétricas que, também, podem ser potencializados para a irrigação ou abastecimento público. "De fato, a agricultura irrigada e, em certa extensão, o abastecimento urbano, são grandes competidoras da geração hidráulica pelo uso da água em sistemas hídricos" (Fernandez; Garrido, 2003, p.468).

Os marcos regulatórios são fundamentais para definir investimentos no setor e definir ações de conservação e recuperação dos recursos hídricos. Isso consiste em gerir os recursos hídricos, de forma integrada, com vistas à manutenção da produção de água e à garantia da qualidade da água. Entretanto, o uso compartilhado da água para abastecimento e geração de energia elétrica é passível de conflitos, pois a geração de energia independe de níveis superiores de qualidade, assim como exigem o aproveitamento hídrico para o abastecimento público. Nesse sentido, foi feita a respectiva indagação referente à preocupação da empresa com uma gestão participativa que visa reduzir os conflitos pelo uso da água. Esse questionamento foi feito aos entrevistados da Emae:

- A geração hidroenergética e o abastecimento público tem se tornado um dos grandes desafios para administrações e comunidades atuais. Visando os usos múltiplos da água a empresa promove uma gestão participativa para a redução dos conflitos? Justifique.

Para RE1, almejar uma gestão participativa é meta da empresa, porém as perspectivas que a concretizam estão mais reduzidas; por enxergar possibilidades muito distantes de uma política pública capaz de arregimentar os esforços:

O que percebo é infelizmente uma visão imediatista e políticas desconexas, em especial entre os diferentes municípios que compõe a bacia da Billings. Interesses conflitantes, necessidade de expansão urbana sobre as áreas de mananciais e setores econômicos e políticos determinando o uso do solo. Acho que o exemplo mais bem-sucedido nesse campo é o exemplo da cidade de Extrema, no sul de Minas, que remunera o produtor de água, incentiva 
o plantio e recomposição de florestas e consegue visualizar o proprietário como um parceiro e não como um empecilho ao desenvolvimento econômico (REl).

Para o(a) entrevistado(a), o comprometimento financeiro do usuário de recursos ambientais pode contribuir para manutenção dos recursos e reduzir a propensão de ameaças ao meio ambiente.

Os riscos aos recursos ambientais se intensificam, mas dificilmente convertem politicamente num conjunto de medidas preventivas para a superação das causas que convergem nos riscos, e " [...] não se sabe ao certo qual o tipo de política e de instituições políticas que estariam em condições de adotá-las. O que surge, na verdade, é uma solidariedade ininteligível, correspondente à ininteligibilidade dos riscos" (Beck, 2001, p.58).

A ampliação dos passivos ambientais que atingem os reservatórios acentua os conflitos e exigem uma gestão participativa que envolva a sociedade civil nas ações o uso e conservação dos recursos hídricos. Para isso é necessário que todos os atores envolvidos tenham a dimensão dos riscos, e é importante que informações claras e objetivas atinjam os mais distintos segmentos da sociedade, ao considerar a água um recurso natural de uso comum.

Para RE2, a atribuição para a gestão participativa deve ser coordenada pelo primeiro setor (Estado). Apesar disso, a empresa (Emae) já promoveu no passado trabalhos de inserção socioambiental, na busca de capacitar as comunidades locais para se apoderar medidas de conservação ambiental, porém não foram adiante devido principalmente à falta de recursos.

Nesse sentido, é fundamental a capacitação das comunidades locais à luz das experiências socioambientais cotidianas, as quais podem impedir a ocorrência de futuros riscos ambientais. Sendo que os riscos são mais suscetíveis a população de baixa renda, que são oneradas no longo prazo por conta de diversos poluentes no ar, na água e no solo (Beck, 2011).

O adensamento urbano aliado à ineficiência na execução das legislações ambientais contribuíram para a ocupação das áreas de mananciais do reservatório Billings, isso abriu precedentes para que ocorressem impactos socioambientais que comprometem a quantidade e qualidade da água.

O Quadro 1 reúne os fatores aos destacam os atores envolvidos nos impactos socioambientais suscetíveis de conflitos.

$\mathrm{Na}$ perspectiva da realidade presente no reservatório de Barra Bonita, inserido na bacia do rio Tietê, ao representante da operadora privada AES-Tietê foi feita a seguinte indagação:

- Como se posiciona os gestores de um reservatório quando ocorre a pressão sobre os recursos hídricos em detrimento do conflito entre alta demanda pelos abastecimentos público, e o setor hidrenergético? Existe um modelo de atuação do setor energético na gestão do reservatório? 
Quadro 1 - Impactos socioambientais suscetíveis de conflitos

\begin{tabular}{|c|c|c|}
\hline Atores & Impactos socioambientais & Conflitos \\
\hline $\begin{array}{l}\text { Prefeituras e empresa } \\
\text { que opera reservatório }\end{array}$ & $\begin{array}{l}\text { Ocupação desordenada } \\
\text { e falta de tratamento } \\
\text { de efluentes em áreas } \\
\text { mananciais do reservatório }\end{array}$ & $\begin{array}{l}\text { Investimentos insuficientes } \\
\text { em habitação e de fiscalização }\end{array}$ \\
\hline $\begin{array}{l}\text { Empresa que opera reservatório } \\
\text { e o Ministério Público }\end{array}$ & $\begin{array}{l}\text { Lançamento contínuo } \\
\text { de águas do rio Pinheiros } \\
\text { no reservatório Billings }\end{array}$ & $\begin{array}{l}\text { Impedimento do Ministério } \\
\text { Público ao projeto de flotação }\end{array}$ \\
\hline $\begin{array}{l}\text { Grandes empreendimentos } \\
\text { e concessionária de rodovias }\end{array}$ & $\begin{array}{l}\text { Assoreamento } \\
\text { e desflorestamento } \\
\text { em áreas de mananciais }\end{array}$ & $\begin{array}{l}\text { Morosidade na compensação } \\
\text { ambiental após a conclusão } \\
\text { da obra rodoviária }\end{array}$ \\
\hline
\end{tabular}

Fonte: Elaborado pelos autores.

Na perspectiva desse questionamento, cabe à empresa que opera o reservatório regular a vazão do reservatório, principalmente em situações de escassez hídrica sob o risco de comprometer turbinas e geradores da usina. Porém, envolvem decisões operacionais que impactam os múltiplos usos e motivam conflitos ao impedir a utilização do reservatório para navegação, irrigação e pesca (Galvão; Bermann, 2015). Diante dessa realidade relacionada aos conflitos, RA os autores afirmam que:

A AES Tietê em atenção às recomendações dos órgãos competentes e pelas condições hidrológicas restritivas que afetem seus reservatórios preza pelo uso múltiplo deste ativo. Diariamente são realizadas simulações/ estudos sobre as condições hidrológicas dos reservatórios e medidas operacionais são tomadas a partir destes estudos. Tal medida é realizada atendendo recomendações de órgãos como ANEEL - Agência Nacional de Energia Elétrica, ONS - Operador Nacional do Sistema e IBAMA, a fim de preservar os níveis da represa, evitar o esgotamento do recurso hídrico na localidade e eventual dano ao meio ambiente e todos os seus usuários múltiplos (RA).

Dentre as recomendações exigidas pela Aneel, destaca-se a avaliação do assoreamento em reservatórios. É necessário que o operador do reservatório realize com regularidade os níveis de granulometria em suspensão e do leito. Também é necessária a medida da carga de fundo em estudos sedimentológicos para pequenos e médios reservatórios, uma vez que o sedimento grosso (areia) nunca é descarregado pelos condutos e vertedouro, ficando depositado no reservatório; com exceção para pequena quantidade de areia descarregada em ocasião de enchentes (Aneel, 2000).

Segundo Campagnoli (2012), para a gestão integrada de reservatórios hidrelétricos é vital a preservação do potencial hidráulico. Pois o adequado gerenciamento do lago, de suas áreas marginais e da bacia contribuinte pode 
proporcionar uma sobrevida maior ao aproveitamento hidrelétrico para novos contratos e concessões.

Entretanto, o(a) entrevistado(a) não cita o envolvimento de outras instituições tendo em vista uma gestão compartilhada para o uso e manutenção do reservatório. A participação de outras instituições ocorre somente para o cumprimento de determinações previstas para o estabelecimento da concessão.

A AES, no último relatório, ressalta a proporção de energia produzida de acordo com o regime de chuvas ocorridas em 2014. Os níveis dos reservatórios da região Sudeste encerraram 2014 com cerca de 19,4\% da sua capacidade total, inferior aos níveis verificados no final de dezembro de 2013 , que foi de $43 \%$ (AES, 2014).

Em um país extremamente dependente da geração hidrelétrica, a compreensão da crise hídrica envolve a valorização do recurso hídrico como bem público finito e a conscientização de um uso mais racional e compartilhado da água são essenciais para garantir da oferta hídrica para os usos múltiplos. Para isso, é necessário aprimorar técnicas de reúso da água, reduzir o desperdício pelos diferentes setores usuários, além de implementar ações de conservação de mananciais e de investimento em infraestrutura com foco na segurança hídrica de forma a garantir maior capacidade de reservação e de acesso à água (ANA, 2016).

Segundo Acselrad (2004), os conflitos ambientais podem ser compreendidos de duas formas: o primeiro, o conflito por distribuição de externalidades, proveniente da dificuldade dos geradores de impactos externos assumiram a responsabilidade por suas consequências; o segundo está associado ao conflito pelo uso dos recursos naturais, decorrente da dificuldade de se definir propriedade sobre os recursos: "Os conflitos, nesta perspectiva, estariam associados aos espaços sociais que escapam à ação do mercado, envolvendo recursos que não tem preço e que não são objetos de apropriação privada" (Acselrad, 2004, p.18).

Nesse sentido, ao considerar a água um recurso ambiental de uso comum impedida de ser apropriada de forma privada, foi feita a seguinte questionamento aos(as) entrevistado(as) da Sabesp:

- Como se posiciona os gestores de um reservatório quando ocorre a pressão sobre os recursos hidricos em detrimento do conflito entre alta demanda pelo do setor de saneamento na gestão do reservatório?

$\mathrm{O}$ (a) entrevistado(a) RS afirma que o ciclo do saneamento básico (água e esgoto), denominado Saneamento Ambiental Tarifado, tem etapas amplamente sedimentadas na cultura organizacional da Sabesp e de todas as outras companhias de saneamento básico estaduais existentes no Brasil. Inclusive, antes do marco regulatório do setor de saneamento (Lei Federal n.11.445/07) havia empresas estaduais que cuidavam apenas da distribuição de água e não tinham a atribuição de operar o sistema público de esgotamento sanitário; também não tinham a obrigação de universalizar com equidade saneamento rural dentro de uma cidade sob concessão. 
A Sabesp é uma empresa de economia mista, que tem o governo do estado de São Paulo como principal acionista, o que a caracteriza como uma empresa pública. Mesmo assim, empresas de saneamento de capital misto abdicam o Estado de exercer a aplicação de recursos obtidos com impostos nas demandas evidenciadas pelo setor de saneamento, e deixando-o na condição de investidor, o qual busca viabilizar o seu lucro nas ações que detém e, também, cria agências de regulação no interior do seu aparelho gestor.

Para que essas medidas sejam implantadas é fundamental uma articulação permanente entre municípios, estados, União e demais responsáveis pela gestão das águas. Isso consiste em superar a falácia de que manter rios limpos é difícil, caro, e por isso não vale o esforço. Valorizar as ações que promovam o saneamento básico proporciona redução dos custos com relação à saúde pública (Granziera, 2014).

Segundo RS, no setor de saneamento é preciso analisar dois instantes, entre os anos 2003 e 2013. Em 2003 houve um ciclo hidrológico seco em toda a Região Metropolitana de São Paulo, podendo ser questionada a magnitude, mas em 2013 houve um ciclo de estiagem que foi administrado por uma visão operacional (técnica). Não existiu o envolvimento de agências reguladoras, e a Sabesp se concentrou na gestão dos níveis do reservatório do Cantareira até o último minuto sem o envolvido de outras instituições e pressionada pela demanda por água, mas houve uma sequência de chuvas de verão, que recuperou os níveis dos seis lagos do reservatório do Cantareira $50 \%$ do abastecimento da conurbação urbana.

Além das questões pluviométricas, outros fatores contribuíram para a diminuição da disponibilidade de água, como a ampliação do abastecimento público devido ao aumento populacional, consequentemente aumento da ocupação do solo proporcionando mudanças nos níveis de infiltração e escoamento da água e aumento de atividades produtivas poluidoras e assentamentos irregulares, contribuindo o lançamento de efluentes não tratados (Galvão; Bermann, 2015).

Para RS, o excesso de reservação de água em 2011, no sistema Cantareira, e com distanciamento nas discussões institucionalizadas entre Ministério Público estadual, Arsesp e a Sabesp, fez que a Sabesp não estruturasse efetivamente um plano de ampliação da oferta de água bruta (insumos), tornando-se, em anos posteriores, um estopim para a crise hídrica que atingiu o sistema Cantareira.

O uso múltiplo das águas em reservatórios é um tema complexo. Ainda faltam mecanismos institucionais que disciplinem de forma adequada como gerenciar os conflitos entre a geração de energia e demais usos (Galvão; Bermann, 2015).

Nessa perspectiva, foi indagado ao entrevistado RF, representante da CFTP:

- Como se posiciona a Capitania Fluvial do Tietê-Paraná no reservatório de Barra Bonita quando ocorre a pressão sobre os recursos hídricos em detri- 
mento do conflito entre alta demanda pelo abastecimento público, e o setor bidrenergético? Existe um modelo de atuação do setor energético na salvaguarda da vida humana e prevenção da poluição hídrica do reservatório?

Sobre a questão, RF diz que a premissa da instituição à qual representa busca garantir a segurança da navegação, salvaguarda da vida humana e prevenção da poluição hídrica. Sobre os conflitos relacionados aos recursos hídricos, a CFTP reitera que não tem a atribuição de definir os níveis dos reservatórios existentes na Hidrovia. Convém mencionar que o Departamento Hidroviário (DH) da Secretaria de Logística e Transportes do Governo do Estado de São Paulo é responsável pela administração do Rio Tietê.

Desde a formação do reservatório de Barra Bonita a disputa de interesses entre os atores na área impactada pela construção da usina tem evidenciado os possíveis conflitos ocorridos ao longo do seu processo histórico, como pode ser destacado no Quadro 2.

Quadro 2 - Histórico dos possíveis conflitos ocorridos no reservatório de Barra Bonita

\begin{tabular}{|c|c|c|}
\hline Atores & Impactos socioambientais & Conflitos \\
\hline Oleiros e construtores da usina & $\begin{array}{l}\text { Comprometimento } \\
\text { da produção ceramista } \\
\text { e inundação de várzeas }\end{array}$ & $\begin{array}{l}\text { Atividade ceramista } \\
\text { e geração de energia }\end{array}$ \\
\hline Geração de energia e hidrovia & $\begin{array}{l}\text { Desequilíbrio no aporte } \\
\text { hídrico em situações } \\
\text { de escassez hídrica }\end{array}$ & $\begin{array}{l}\text { Manter a vazão do reservatório } \\
\text { e garantir a navegabilidade }\end{array}$ \\
\hline Sociedade civil e poder público & $\begin{array}{l}\text { Ocupações irregulares, } \\
\text { desmatamento } \\
\text { e assoreamento }\end{array}$ & $\begin{array}{l}\text { Uso e ocupação do solo } \\
\text { e responsabilidade } \\
\text { na destinação de efluentes } \\
\text { não tratados }\end{array}$ \\
\hline
\end{tabular}

Fonte: Elaborado pelos autores.

Nessa perspectiva, o reservatório de Barra Bonita, construído com o objetivo de suprir a demanda por energia elétrica, promoveu intensas transformações na economia regional, favorecendo os múltiplos usos das águas disponíveis na bacia hidrográfica do rio Tietê. Esse estímulo econômico contribuiu para o crescimento urbano, que por sua vez dificilmente possui os recursos provenientes da geração de energia para atender a todos os critérios que atendem ao saneamento ambiental.

Outro caso grave nos reservatórios é a presença (a concentração) em altos níveis de fertilizantes e agrotóxicos utilizados em grande escala nas áreas agrícolas, praticamente em toda extensão do rio. Diga-se de passagem, nos seus $2.200 \mathrm{~km}$, levando em consideração suas duas margens. Cito em especial, os imensos canaviais que circundam não apenas suas margens, mas a 
maior parte das terras drenadas pelas suas bacias. A presença desses produtos contribui significativamente para a proliferação das algas cianofíceas (algas azuis) altamente prejudiciais ao rio ( $\mathbf{R F})$.

Segundo RF, há ausência quase que total de mata ciliar. Essa amenizaria (reteria ou poderia absorver) grandes quantidades dos produtos utilizados nas lavouras, além de evitar o desbarrancamento das margens e consequentemente evitaria o assoreamento: "A irreversibilidade da urbanização exige uma maior atenção do debate ambiental às cidades, inclusive propondo a radical revisão do modo como elas se relacionam com seus cursos d'água” (Anelli, 2015, p.69).

No âmbito da fiscalização de usos de recursos hídricos visando priorizar a segurança hídrica é fundamental que haja aumento da quantidade de campanhas de fiscalização em campo, com apoio de imagens de satélite; com o cumprimento das regras de restrição de uso da água com os usuários de recursos hídricos; verificação de defluência de reservatórios e articulação com órgãos gestores estaduais e municipais (ANA, 2016).

É evidente que poluição hídrica, desmatamento e ocupação de mananciais, falta de planejamento na construção de novos reservatórios, falta de investimentos para redução de perdas de água e falta de cooperação entre instituições são resultados de ações fragmentadas de gestores dos recursos hídricos preocupados em atender as demandas de curto prazo de forma a controlar investimentos para pilhar recursos financeiros. Com isso, as instituições direcionam seus investimentos em ações que visam ampliar os lucros, trazendo benefícios de curto prazo.

A Resolução Conama 357/05, em consonância com o Decreto Estadual n.8.468 (São Paulo, 1976), define critérios para uso e ocupação de mananciais, e fixa limites para emissão e efluentes. Sendo a responsabilidade pela fiscalização atribuída à Cetesb, portanto cabe a essa empresa, também, orientar as ações desempenhadas por usuário e operadores de reservatório, como trata na respectiva questão:

- A definição do aproveitamento dos recursos hídricos para a geração hidrenergética e para o abastecimento público tem se tornado um dos grandes desafios para os gestores de reservatórios. Visando os usos múltiplos, a Cetesb está envolvida em algum projeto que viabiliza a geração de energia e o abastecimento público nos reservatórios Billings e de Barra Bonita?

Sim, por força de sua atribuição em licenciar essas atividades e monitorar os corpos de água. Em especial o reservatório Billings está no centro das discussões, pois vai haver a retirada de $5 \mathrm{~m}^{3} / \mathrm{s}$ desse reservatório para o Taiaçupeba; e ainda, por conta da geração de energia, sempre volta à tona a despoluição do rio Pinheiros para retomar o bombeamento daquele rio para a Billings para voltar a turbinar em Henry Borden. O reservatório de Barra Bonita também está contemplado como um possível futuro manancial para a RMSP por meio dos estudos da "Macrometrópole Paulista". É bom lembrar que os usos múltiplos devem estar submetidos ao que estabelece a Política Nacional de Recursos Hídricos sobre os usos prioritários da água para abastecimento público (RC). 
É identificado o envolvimento da respectiva empresa pública no monitoramento de ambos os reservatórios, e a preocupação com relação ao aporte hídrico e qualidade da água tendo em vista o crescimento urbano e uma possível ampliação da demanda por mananciais disponíveis ao abastecimento público.

$\mathrm{Na}$ perspectiva da AES-Tietê o monitoramento do reservatório de Barra Bonita tem sido atendido por investimentos tecnológicos que objetivam o acompanhamento dos índices de qualidade da água por meio do seguinte questionamento:

- A empresa se envolve em projetos de redução dos passivos ambientais em reservatórios? Quais? Esses projetos têm a participação de outras empresas públicas ou privadas?

Para RA, é importante para a empresa assegurar a preservação das bordas de seus reservatórios, e isso é garantido por meio uma área específica criada desde 2013 para a realização da Gestão dos Reservatórios. Para fiscalização e gestão dos reservatórios, a empresa dispõe de equipe especializada, além de equipamentos modernos de alta precisão como: três drones, sendo dois Veículos Aéreos Não Tripulados (Vant) e um barco telecontrolado para medições de vazões, velocidade e batimetria. Os Vant sobrevoam os reservatórios em busca de possíveis alterações ambientais; tais tecnologias é resultado de um investimento de R\$ 2 milhões em equipamentos.

Essa explanação ressalta os investimentos de tecnologias voltadas para o sensoriamento remoto, o que torna monitoramento mais eficiente em uma região potencializada para o desenvolvimento de atividades agrícolas, onde tais atividades podem se estender para os mananciais do reservatório.

No caso do reservatório Billings, foi construído para ampliar a geração de energia a ser ofertada à crescente malha urbana de expansão industrial paulista, dobrando a ocupação da área territorial já consolidada. O processo acelerado de urbanização sem a devida discussão para a criação de leis ambientais e formas de fiscalização fez que se intensificassem o uso e a ocupação do solo de forma desordenada, utilizando rios para diluir e afastar o esgoto, drenando e aterrando várzeas para construção de infraestruturas urbanas.

A Região Metropolitana de São Paulo inserida em uma área de insuficiência disponibilidade hídrica, em quantidade e qualidade, teve seus cursos hídricos atingidos por obras de canalização, transposição e alteração no trecho de rios, como é o caso do rio Pinheiros (ANA, 2016).

O reservatório Billings, em situações esporádicas, é servido pelas águas poluídas do rio Pinheiros, o qual foi revertido com o objetivo de garantir o aporte hídrico do reservatório Billings. A partir da importância dessa reversão de águas para o reservatório Billings foi feita a seguinte pergunta:

- O impedimento do bombeamento contínuo e sistemático das águas do rio Pinheiros, em consequência da má qualidade da água, para o reservatório Billings trouxe consequências para a produção hidrenergética da usina 
Henry Borden. Por isso a operação do reservatório deveria ser realizada em conjunto, setor elétrico e saneamento? Justifique.

Está cada vez mais evidenciado que sem o bombeamento, tanto o setor elétrico, quanto o de saneamento ficariam prejudicados, caso contrário a compartimentação do reservatório, proposta no passado já estaria colocada em prática, privilegiando o abastecimento público. O que é preciso dizer é que a Billings prescinde da água do Tietê, e sem ela não poderíamos hoje recuperar os volumes da Guarapiranga e tentar reerguer o sistema Alto Tietê. Nesse sentido o governo vem estudando alternativas para manter um bombeamento capaz de cumprir esse papel. Pela primeira vez, em mais de 20 anos da publicação da Resolução Conjunta que determinou a parada do bombeamento, o Estado vem a público e propõe soluções para a recuperação dos volumes da Billings incluindo a retomada da geração em Henry Borden, avaliando os erros do passado com a flotação, estudando novas alternativas, a composição de sistemas de tratamento e não um só tipo de sistema, incorporando novas tecnologias ( REl).

Segundo Gramulia Jr. (2009), a importância do bombeamento do rio Pinheiro é ressaltada a partir do cálculo referente à geração energia elétrica produzida de 1997 até 2008 com a respectiva potência média; caso não houvesse impedimentos legais o valor faturado na geração de energia seria de aproximadamente R\$ 3,67 bilhões. Esse faturamento poderia contribuir com iniciativas de despoluição dos rios Tietê e Pinheiros, melhorando a qualidade da água nos reservatórios Billings e de Barra Bonita.

RE2 diz que a empresa mantém representação e participação junto aos comitês de bacias hidrográficas da sua área de concessão. Apesar da participação intersetorial (governo, empresas e sociedade civil) as empresas agem de maneira a defender os seus interesses e pouco integrada. Por isso, a integração de interesses traria benefícios aos usos múltiplos do reservatório, como o abastecimento público e produção hidrenergética.

De acordo com a Lei n.13.579 (São Paulo, 2009), dentro do artigo $8^{\circ}$, cabe aos órgãos da administração pública estadual e municipal efetuar licenciamento, regularização, aplicação de mecanismos de compensação, fiscalização e monitoramento da qualidade ambiental; assim como promover, implantar e exercer a fiscalização integrada com demais entidades participantes do Sistema de Planejamento e Gestão e com os diversos sistemas institucionalizados.

Nesse sentido, é fundamental coibir a ocupação desordenada por meio de propostas de urbanização que tenham como finalidade a estruturação de redes de coleta de efluentes, e não somente a garantia fornecimento de água, eletrificação e pavimentação de vias; propostas muito comuns desempenhadas por governos municipais. Sendo assim, é importante que as empresas exerçam ações voltadas para o saneamento e estejam engajadas com os projetos de urbanização. Além disso, é fundamental envolver as empresas que operarem os reservatórios 
em ações promovidas pelos governos municipais com o objetivo de promover a garantia de qualidade e quantidade de águas dos reservatórios.

No que se refere à participação de ações integradas entre empresas de saneamento e de monitoramento (Cetesb), foi feita a seguinte pergunta:

- Existe um diálogo entre a Cetesb com as empresas de saneamento? Caso a resposta seja afirmativa, em que momentos houveram práticas integradas de preservação dos recursos hidricos? Caso a resposta seja negativa, qual é o impedimento para que tais práticas integradas sejam efetivadas?

RC afirma que existem, porém são práticas integradas estabelecidas em um longo e difícil processo em constante construção. Por exemplo, em momentos de escassez hídrica como ocorrida nos últimos anos, as ações são planejadas, informadas e executadas para atender os anseios da imprensa e nem sempre discutidas com antecedência entre os órgãos ou nos comitês de Bacia.

No contexto dos comitês de bacia no Brasil, as discussões são controladas por grupos dotados de conhecimento técnico e discurso sofisticado, privilegiando, dessa forma, representantes do Estado e do setor privado, e favorecendo as decisões de acordo com os interesses econômicos presentes na região. Com isso, agendas políticas e interesses econômicos são camuflados e inseridos nas discussões por meio de uma linguagem técnica objetiva e racional (Empinotti, 2011).

É importante ressaltar que apesar de os comitês de bacias serem espaços de deliberação, conforme está previsto na Lei n.9.433, na prática o Estado ainda os considera como órgãos consultivos, mas não deliberativos; o que leva a tensões entre os órgãos setoriais e a sociedade civil organizada (Empinotti, 2011).

Os períodos de escassez hídrica tendem a ser recorrentes devido às variações das condições climáticas atuais evidenciadas por secas em algumas partes do mundo e aumento de inundações em outras, decorrentes de uma aceleração da variabilidade na quantidade e distribuição das chuvas (Silva, 2015).

O consumo de água é impulsionado por fatores relacionados ao crescimento populacional e aumento da renda per capita, o que reduz a percepção do valor cobrado pelo uso da água. No estado de São Paulo, por exemplo, ao invés de o valor ser um instrumento de controle do consumo pelo aumento da tarifação, a estratégia adotada pela Sabesp foi inversa, reduzindo o valor da conta para aqueles que diminuíssem o consumo (Silva, 2015). Tal medida preocupa-se em exercer uma gestão de oferta, mas não uma gestão que atenda demandas futuras.

É necessária uma óptica mais abrangente e sistêmica da problemática da água em todo o estado de São Paulo, e o aprimoramento de seus instrumentos pode tornar as medidas atuais, emergenciais e paliativas em uma gestão estratégica focada na sustentabilidade hídrica.

Em situação de escassez hídrica, a Sabesp desempenhou várias ações para garantir o abastecimento público, inclusive alterando o sistema hidrológico de reservatórios. O reservatório Billings, por exemplo, em vários momentos teve seu aporte hídrico aproveitado para suprir a demanda por água de outros reser- 
vatórios e regiões, devido aos altos índices pluviométricos e regulares que atinge a sua Bacia ao longo do ano.

Nesse caso, os dilemas, ao exercer uma ação coletiva, são decorrentes das interações entre diferentes atores envolvidos, cada um com seus valores e preferencias, e todos na busca em maximizar seus níveis de satisfação (Caldas, 2007). Exercer um diálogo entre empresas de energia e de saneamento é um desafio devido aos seus interesses antagônicos diante de um recurso de uso comum, a água.

O cumprimento das agendas de governo visa aplicar as políticas públicas em um ambiente em que forças políticas e sociais estão em constante disputa. Os papéis desempenhados por instituições e atores são fundamentais na intermediação de conflitos e interesses presentes nos processos de formação de agenda (Caldas, 2007).

A garantia de aporte hídrico e de qualidade da água em reservatórios contempla tanto empresas geradoras de energia como de saneamento, além dos atores que monitoram o reservatório, onde seus resultados confluem em melhoria das condições do reservatório.

O Quadro 3 apresenta um cenário do modelo de gestão executado pelas instituições, os conflitos em que estão envolvidas e os passivos ambientais identificados nos respectivos reservatórios em que atuam. Essa iniciativa em curso busca ampliar o diálogo sobre um novo modelo de gestão que garanta a segurança hídrica e a manutenção de ações compartilhadas que sustentabilidade hídrica dos reservatórios.

A partir do Quadro 3, pode-se identificar um discurso normativo e distante de qualquer integração entre as instituições, assim como afastado do envolvimento da sociedade para o enfrentamento dos passivos ambientais. Nesse caso, há um distanciamento de possíveis ações compartilhadas entre as instituições que defendem interesses próprios diante de um bem comum, a água.

$\mathrm{O}$ distanciamento entre as instituições que atuam no reservatório as deixa suscetíveis à possibilidade de má alocação dos recursos e dificulta o acesso a incentivos fiscais para a manutenção do reservatório, quando não há participação efetiva de representantes da sociedade civil.

\section{Conclusões}

Os conflitos podem gerar efeitos motivadores para que os atores envolvidos busquem soluções que reduzam os seus efeitos, possibilitando o início de uma gestão compartilhada. Mesmo que nas instituições haja interesses políticos antagônicos, é importante existir momentos de confluências de interesses entre os diferentes atores aos quais exercem alguma atuação nos reservatórios hidrelétricos.

O desenvolvimento vocacionado para a aceleração incontrolada do crescimento econômico reduz as possibilidades de ações compartilhadas em prol 
Quadro 3 - Síntese das respostas das entrevistas

\begin{tabular}{|c|c|c|c|}
\hline $\begin{array}{c}\text { Atores } \\
\text { envolvidos }\end{array}$ & $\begin{array}{c}\text { Gestão de "Recuros } \\
\text { Limitados" }\end{array}$ & Conflitos & Passivos \\
\hline Emae & $\begin{array}{l}\text { Recurso limitado para } \\
\text { a realização de } \\
\text { monitoramento/fiscali- } \\
\text { zação }\end{array}$ & $\begin{array}{l}\text { Impedimento } \\
\text { do bombeamento das } \\
\text { águas do rio Pinheiros }\end{array}$ & $\begin{array}{l}\text { Poluição do reservatório } \\
\text { e ocupação } \\
\text { desordenada }\end{array}$ \\
\hline Cetesb & $\begin{array}{l}\text { Parceria com outras } \\
\text { instituições } \\
\text { tem favorecido } \\
\text { as propostas } \\
\text { de trabalho }\end{array}$ & $\begin{array}{l}\text { Falta de diálogo mais } \\
\text { intenso entre os atores } \\
\text { antes de publicado } \\
\text { a imprensa }\end{array}$ & $\begin{array}{l}\text { Poluição do Rio } \\
\text { Pinheiros }\end{array}$ \\
\hline Sabesp & $\begin{array}{l}\text { Falta de um plano } \\
\text { emergencial efetivo } \\
\text { para ampliação } \\
\text { de oferta de água para } \\
\text { a prevenção de crises } \\
\text { hídricas }\end{array}$ & $\begin{array}{l}\text { Distanciamento } \\
\text { das discussões } \\
\text { com o setor energético }\end{array}$ & Poluição do Rio Tietê \\
\hline AES-Tietê & $\begin{array}{l}\text { Criação de uma área } \\
\text { específica de gestão } \\
\text { de reservatórios } \\
\text { que assegura alto } \\
\text { investimento em } \\
\text { monitoramento }\end{array}$ & $\begin{array}{l}\text { Redução da vazão } \\
\text { situação de escassez } \\
\text { hídrica }\end{array}$ & $\begin{array}{l}\text { Desmatamento de mata } \\
\text { ciliar e poluição hídrica }\end{array}$ \\
\hline CFTP & $\begin{array}{l}\text { Garantir } \\
\text { a salvaguarda } \\
\text { da vida humana } \\
\text { e na prevenção } \\
\text { da poluição hídrica }\end{array}$ & $\begin{array}{l}\text { Os atores poderiam } \\
\text { ampliar aspectos } \\
\text { sobre gestão e função }\end{array}$ & Poluição hídrica \\
\hline
\end{tabular}

Fonte: Elaborado pelos autores.

de melhorias socioambientais, pois a garantia dos interesses individuais é a base da sociedade de mercado como forma de não dividir os lucros e direcionar os investimentos para manter somente o crescimento econômico.

Dentro da realidade do grau de desenvolvimento é necessário que haja capacidade de organização institucional articulada de forma adequada com as demais instituições. Exercer ações compartilhadas é estimular parcerias entre operadores de usinas hidrelétricas, empresas de saneamento, entidade públicas (federais, estaduais e municipais), a fim de tornar concretas as propostas de preservação dos reservatórios e redução dos conflitos.

Isso consiste em fortalecer as instituições com o objetivo de que elas atendam de forma eficiente as legislações vigentes. Mesmo assim, é fundamental que as agências reguladoras atuem de forma sistemática e rigorosa sobre o funcionamento das usinas hidrelétricas públicas e privadas, para que não haja conflitos operacionais em detrimento do lucro financeiro. 
Para isso, é importante criar canais de comunicação entre os atores em espaços de diálogo com o objetivo de construir relações interinstitucionais entre os atores que defendem interesses díspares, possibilitando uma convergência que resulte em melhorias para o reservatório. Isso inclui desenvolver de instrumentos técnicos de uso compartilhado para mensurar os passivos ambientais em curto e em longo prazo.

É muito importante internalizar nas políticas de governo a discussão sobre os custos ambientais e energéticos provenientes da produção agrícola e industrial quando exportada para outros países, pois grande parte da água e energia utilizada nas atividades de prospecção dos produtos que são exportados não é calculada como custo exclusivo relacionado à geração de energia ou passivos ambientais oriundos de atividades produtivas. Incluir os custos ambientais no sistema produtivo pode ser uma prática que reduza os conflitos ambientais

No caso das usinas hidrelétricas, os setores de produção de energia e de saneamento promovem ações de forma dissociada, fato que justifica a escalada dos passivos ambientais que atingem o reservatório. $\mathrm{E}$ os agentes sociais locais acompanham passivamente as decisões elencadas pelos setores elétricos e de saneamento.

É fundamental conhecer os passivos ambientais presentes nos reservatórios hidrelétricos Billings e Barra Bonita quantificando-os e qualificando-os, e criar instrumentos econômicos para viabilizar ações compartilhadas entre atores envolvidos. Porque, isoladamente, os atuais mecanismos de recuperação desses reservatórios estão distantes de atingir resultados plenos dentro dos aspectos socioambientais.

As considerações feitas pelos entrevistados que colaboraram com a pesquisa visam indicar problemas e caminhos para auxiliar os gestores públicos. Foram identificados aspectos positivos e negativos na gestão pública e privada, evidenciando lacunas nas práticas compartilhadas e mostrando a importância de criar caminhos para a construção de práticas integradas entre ambas para melhor preservação dos mananciais dos reservatórios Billings e Barra Bonita, empregando critérios que viabilizem a concomitância do abastecimento público e o aproveitamento energético.

A gestão de reservatórios, seja pública, seja privada, é dinâmica, pois em todos os momentos surgem variáveis que alteram todo o conjunto de conflitos estabelecidos, de forma que ações engessadas de atuação dificilmente evoluem para possíveis melhorias socioambientais nos reservatórios. Nesse sentido, a empresa privada analisada se destaca nas inovações tecnológicas quanto ao monitoramento do reservatório, e a empresa pública atua de forma mais eficiente com a comunidade local.

Todavia, no reservatório de Barra Bonita, construído com o objetivo principal de ampliar a capacidade de geração de energia elétrica, outras atividades econômicas passaram a gerar conflitos quanto ao uso da água, dentre as quais se 
destaca a irrigação, a extração de areia, a navegação (hidrovia Tietê-Paraná) e o abastecimento público. Em situação de escassez hídrica, as instituições atuantes nos respectivos setores estão sujeitas a conflitos, pois o aproveitamento operacional do reservatório é distinto para cada ator envolvido.

Nesse caso, é fundamental o envolvimento, mesmo que parta da iniciativa privada, entre usuários, operadores e a sociedade civil organizada; isso consiste em reconhecer possíveis conflitos e desenvolver diálogos que atinjam pontos de equilíbrio entres os atores envolvidos almejando evitar desacordos e decisões conflitivas.

As ações conflitantes pelo uso da água entre os usuários e operadores dos reservatórios podem configurar-se em um cenário de elaboração de medidas que reduzam os passivos ambientais que atingem os reservatórios. Tais medidas consistem em garantir o uso compartilhado do reservatório com o mínimo de conflitos entre o uso energético e o abastecimento público.

Para que haja uma gestão de recursos hídricos de forma integrada, exige-se uma coalizão de forças de diversos atores que utilizam a água como recurso principal na atividade produtiva. Dessa forma, a avaliação da gestão pública é baseada nos investimentos (gastos de recursos) em determinados setores e dificilmente os resultados são devidamente analisados. E são os resultados que podem constituir proposta de qualificação da gestão.

\section{Referências}

ABRANCHES, S. H. A questão da empresa estatal: economia política e interesse público. Revista de Administração de Empresa, Rio de Janeiro, v.4, n.19, p.95-105, out./ dez. 1979.

ACSELRAD, H. As práticas espaciais e o campo dos conflitos ambientais, In: ACSELRAD, H. (Org.) Conflitos ambientais no Brasil. Rio de Janeiro: Relume Dumará, 2004. p.13-35.

AES-TIETÊ. Relatório de Sustentabilidade 2014. São Paulo: AES, 2014. 113p.

ALMEIDA, D. L. Os passivos ambientais no reservatório Billings e os seus impactos na geração hidrenergética da Usina Henry Borden. Santo André, 2010. 156f. Dissertação (Mestrado em Energia) - Centro de Engenharia, Modelagem e Ciências Sociais Aplicadas, Universidade Federal do ABC. Santo André, 2010.

ANA. Agencia Nacional de Águas. Conjuntura dos recursos hídricos no Brasil-Encarte Especial sobre a Crise Hidrica. Disponível em <http://conjuntura.ana.gov.br/docs/ crisehidrica.pdf>. Acesso em: 9 jul. 2016.

ANEEL. Agência Nacional de Energia Elétrica. Guia de avaliação de assoreamento de reservatórios. Brasília, DF, 2000.

ANELLI, R. L. S. Uma nova cidade para as águas urbanas. São Paulo: Estudos Avançados, v.29, n.84, p.69-84, maio-ago. 2015.

BECK, U. Sociedade de risco: rumo a uma outra modernidade. 2.ed. São Paulo: Editora $34,2011$. 
BRASIL. Decreto n.24.643, de 10 de julho de 1934. Resolve decretar o seguinte Código de Águas, cuja execução compete ao Ministério da Agricultura e que vai assinado pelos ministros de Estado. Lex: Coleção de Leis do Brasil, Rio de Janeiro, v.4, p. 679, 1934. Legislação Federal e marginária.

Lei n.9.074, de 7 de julho de 1995. Presidência da República. Casa Civil. Subchefia para Assuntos Jurídicos. Estabelece normas para outorga e prorrogações das concessões e permissões de serviços públicos e dá outras providências. Disponível em <http:// www.planalto.gov.br/ccivil_03/leis/L9074cons.htm>. Acesso em 13 set. 2016.

Lei n.9.433, de 8 de janeiro de 1997. Presidência da República. Casa Civil. Subchefia para Assuntos Jurídicos. Institui a Política Nacional de Recursos Hídricos, cria o Sistema Nacional de Gerenciamento de Recursos Hídricos, regulamenta o inciso XIX do art. 21 da Constituição Federal, e altera o art. $1^{\circ}$ da Lei n.8.001, de 13 de março de 1990, que modificou a Lei n.7.990, de 28 de dezembro de 1989. Disponível em <http://www.planalto.gov.br/ccivil_03/leis/L9433.htm>. Acesso em de 2016.

Lei n.9.984, de 17 de julho de 2000. Dispõe sobre a criação da Agência Nacional de Águas - ANA, entidade federal de implementação da Política Nacional de Recursos Hídricos e de coordenação do Sistema Nacional de Gerenciamento de Recursos Hídricos, e dá outras providências. Diário Oficial da União, Brasília, 18 julho 2000. Disponível em: <http://www.planalto.gov.br/ccivil_03/leis/L9984.htm>. Acesso em: 8 ago. 2016.

CALDAS, E. L. Formação de agendas governamentais locais: o caso dos consórcios intermunicipais. São Paulo, 2007, 227p. Tese (Doutorado em Filosofia) - Faculdade de Filosofia, Letras e Ciências Humanas, Universidade de São Paulo. São Paulo, 2007.

CAMPAGNOLI, F. Gestão de reservatórios de hidrelétricas: o potencial hidráulico da união gerido como recurso renovável. In: CAMPOGNOLI, F.; DINIZ. N. C. (Org.) Gestão de reservatório de hidrelétricas. São Paulo: Oficina de Textos, 2012. p.11-14.

CAMPAGNOLI, F.; TUNDISI, J. G. Desafios na gestão de reservatórios de hidrelétricas no Brasil. In: CAMPOGNOLI, F.; DINIZ. N. C. (Org.) Gestão de reservatório de hidrelétricas. São Paulo: Oficina de Textos, 2012. p.175-82.

CONAMA. Resolução n.357, de 18 de março de 2005. Conselho Nacional do Meio Ambiente. Estabelece a classificação das águas doces, salobras e salinas do Território Nacional. Lex: DOU n.053, Brasília, p.58-63.

EMPINOTTI, V. L. E se eu não quiser participar? O caso da não participação nas eleições do comitê de bacia do Rio São Francisco. Ambiente \& Sociedade, v.14, n.1, p.195211 , jan.-jun. 2011.

EPE. Balanço Energético Nacional 2016: Relatório Síntese ano base 2015. Empresa de Pesquisa Energética. Rio de Janeiro: EPE, 2016.

FERNANDEZ, J. C.; GARRIDO, R. J. S. Impactos da nova política nacional de águas sobre os setores usuários de recursos hídricos. Bahia Análise: Dados, Salvador, v.13, n. esp., p.467-80, 2003.

GALVÃO, J.; BERMANN, C. Crise hídrica e energia: conflito no uso múltiplo das águas. São Paulo: Estudos Avançados, v.29, n.84, p.43-68, maio-ago. 2015.

GOLDEMBERG, J. O rio Pinheiros e o resgate da cidadania e da qualidade de vida. In: SÃO PAULO (Estado). Secretaria do Meio Ambiente. O Rio Pinheiros. São Paulo: SMA, 2002. p.5. 
GOMES, J. L.; BARBIERI, J.C. Gerenciamento de recursos hídricos no Brasil e no estado de São Paulo: um novo modelo de política pública. São Paulo: Cadernos Ebape. $B R$, v.2, n.3, p.1-21, dez. 2004.

GRAMULIA JUNIOR, J. G. Contribuição da Usina Hidroelétrica de Henry Borden para o planejamento da operação de sistemas hidrotérmicos de potência. Santo André, 2009. 80f. Dissertação (Mestrado em Energia) - Centro de Engenharia, Modelagem e Ciências Sociais Aplicadas, Universidade Federal do ABC. Santo André, 2009.

GRANZIERA, M. L. M. Direito de Águas. Jornal Carta Forense, São Paulo, 3 maio 2014. Disponível em: <http://www.cartaforense.com.br/conteudo/entrevistas/direito-de-aguas/14507>. Acesso em: 9 ago. 2016.

JACOBI, P. R. et al. Governança da água no Brasil. In: JACOBI, P. R.; FRACALANZA, A. P.; EMPINOTTI, V. Governança da água no contexto ibero-americano: inovação em processo. São Paulo: GovAmb: Procam USP: Annablume, 2015. p.11-28.

MASSEI, R. A construção da usina bidrelétrica Barra Bonita e a relação Homem-natureza: vozes dissonantes, interesses contraditórios (1940-1970). São Paulo, 2007. 308f. Tese (Doutorado em História) - Programa de Estudos Pós-Graduados em História, Pontifícia Universidade Católica de São Paulo. São Paulo, 2007.

OCDE. Governança dos Recursos Hidricos no Brasil. Organização para A Cooperação e Desenvolvimento Econômico. Paris: OCDE, 2015.

PROAM - INSTITUTO BRASILEIRO DE PROTEÇÃO AMBIENTAL. BILLINGS 81 anos: Impactos Ambientais. São Paulo: PROAM, 2006.

RAMALHO, M. L. Território e macrossistema elétrico nacional: as relações entre privatização, planejamento e corporativismo. São Paulo, 2006. 201f. Dissertação (Mestrado em Geografia Humana) - Faculdade de Filosofia, Letras e Ciências Humanas, Universidade de São Paulo. São Paulo, 2006.

SÃO PAULO (Estado). Decreto n.8.468, de 8 de setembro de 1976. Dispõe sobre a prevenção e controle da poluição do meio ambiente. Diário Oficial, São Paulo, 31 mai. 1976. Disponível em: <www.legislacao.sp.gov.br/dg280202.nsf/a2dc3f553380ee0f83

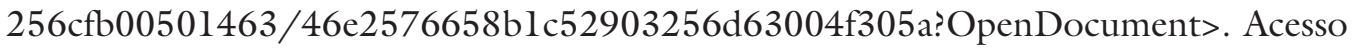
em: 18 julho 2016 .

Lei n.13.579, de 13 de julho de 2009. Define a área de proteção e recuperação dos mananciais Billings - APRA-B, e dá outras providências correlatas. Diário Oficial. São Paulo, 16 setembro 2009. Disponível em: <www.legislacao.sp.gov.br>. Acesso em: 18 julho 2016.

Secretaria do Meio Ambiente. Cadernos de Educação Ambiental: edição especial Billings. São Paulo: SMA/CEA, 2010.

SILVA, D. L. Avaliação da influência de uma campanha de incentivo à redução de consumo de água. Revista Hipótese, Itapetininga, v.1, n.3, p.67-91, 2015.

TAMBOSI, L. R. et al. Funções eco-hidrológicas das florestas nativas e o Código Florestal. São Paulo: Estudos Avançados, v.29, n.84, p.151-62, maio-ago. 2015.

TUNDISI, J. G. Recursos hídricos no futuro: problemas e soluções. Estudos Avançados, São Paulo, v.22, n.63, p.7-16, 2008. 
VAINER, C. B. Recursos hidráulicos: questões sociais e ambientais. Estudos Avançados, São Paulo, v.21, n.59, p.119-37, 2007.

VARGAS, M. C. O negócio da água - riscos e oportunidades das concessões de saneamento à iniciativa privada: estudos de caso no Sudeste brasileiro. São Paulo: Annablume, 2005.

RESUMO: Este trabalho tem como objetivo analisar criticamente a gestão pública do reservatório Billings e a gestão privada do reservatório de Barra Bonita, buscando compreender os conflitos que envolvem o uso dos reservatórios e analisar os fatores que resultam nos principais passivos ambientais. A hipótese geral sustenta a ideia de que a análise dos conflitos pelo uso da água em reservatórios pode contribuir na compreensão da gestão das empresas. Como metodologia, foram aplicadas entrevistas a representantes da Emae, Cetesb, Sabesp, AES-Tietê e CFTP visando compreender os conflitos e os fatores que resultam nos principais passivos ambientais. Os resultados identificaram dificuldades em conduzir uma gestão compartilhada entre os usuários e operadores.

PALAVRAS-CHAVE: Hidrelétricas, Gestão compartilhada, Múltiplos usos da água, Passivos ambientais.

ABSTRACT: This paper is a critical analysis of the public management of the Billings reservoir and of the private management of the Barra Bonita reservoir, and attempts to understand the conflicts involved in the use of these reservoirs as well as the factors that result in major environmental damage. The general hypothesis supports the idea that analyses of conflicts over the use of water in reservoirs may contribute to the understanding of business management. As methodology, representatives from Emae, Cetesb, Sabesp, AES-Tiete and CFTP were interviewed to understand better the conflicts and the factors that result in major environmental damage. The results identified difficulties in shared management between users and operators.

KEYWORDS: Hydroeletric plants, Shared management, Multiple uses of water, Environmental liabilities.

Claudio Luis de Camargo Penteado é doutor em Ciências Sociais e professor do Programa de Pós-Graduação em Energia da Universidade Federal do ABC (SP).

@ - claudio.penteado@ufabc.edu.br

Daniel Ladeira Almeida é doutor em Energia pela Universidade Federal do ABC (SP). $@$ - daniel.ladeira@ufabc.edu.br

Roseli Frederigi Benassi é doutora em Engenharia Hidráulica e Saneamento e professora Programa de Pós-Graduação em Energia da Universidade Federal do ABC (SP).

@ - roseli.benassi@ufabc.edu.br

Recebido em 7.11.2016 e aceito em 20.12.2016.

I, II, III Programa de Pós-Graduação em Energia, Universidade Federal do ABC, Santo André / São Paulo, Brasil. 